\title{
Association of metabolic syndrome traits with urinary biomarkers in Japanese adults
}

\author{
Keiko Kabasawa ${ }^{1,2^{*}}$, Michihiro Hosojima ${ }^{3}$, Yumi Ito ${ }^{1,2}$, Kazuo Matsushima4 ${ }^{4}$ Junta Tanaka ${ }^{1}$, Masanori Hara ${ }^{5}$, \\ Kazutoshi Nakamura ${ }^{6}$, Ichiei Narita ${ }^{1,2}$ and Akihiko Saito ${ }^{7}$
}

\begin{abstract}
Background: Although metabolic syndrome traits are risk factors for chronic kidney disease, few studies have examined their association with urinary biomarkers.

Methods: Urinary biomarkers, including A-megalin, C-megalin, podocalyxin, albumin, $a_{1}$-microglobulin, $\beta_{2}{ }^{-}$ microglobulin, and $N$-acetyl- $\beta$-D-glucosaminidase, were cross-sectionally assessed in 347 individuals (52.7\% men) with a urine albumin-to-creatinine ratio (ACR) $<300 \mathrm{mg} / \mathrm{g}$ in a health checkup. Metabolic syndrome traits were adopted from the National Cholesterol Education Program (third revision) of the Adult Treatment Panel criteria modified for Asians.

Results: Participants had a mean body mass index, estimated glomerular filtration rate (eGFR), and median ACR of $23.0 \mathrm{~kg} / \mathrm{m}^{2}, 74.8 \mathrm{~mL} / \mathrm{min} / 1.73 \mathrm{~m}^{2}$, and $7.5 \mathrm{mg} / \mathrm{g}$, respectively. In age- and sex-adjusted logistic regression analysis, A-megalin and albumin were significantly associated with the clustering number of metabolic syndrome traits (3 or more). After further adjustment with eGFR, higher quartiles of A-megalin and albumin were each independently associated with the clustering number of metabolic syndrome traits (adjusted odds ratio for A-megalin: 1.30 per quartile, 95\% Cl 1.03-1.64; albumin: 1.42 per quartile, 95\% Cl 1.12-1.79).

Conclusions: Both urinary A-megalin and albumin are associated with the clustering number of metabolic syndrome traits. Further research on urinary A-megalin is warranted to examine its role as a potential marker of kidney damage from metabolic risk factors.
\end{abstract}

Keywords: Albuminuria, Urinary biomarker, Chronic kidney disease, Megalin, Metabolic syndrome, Proximal renal tubule

\section{Background}

The kidneys are affected by metabolic syndrome traits, such as abdominal visceral obesity, impaired glucose metabolism, dyslipidemia, and elevated blood pressure [1-3]. The clustering of these traits has been considered to indicate a pre-disease state of lifestyle-related diseases and to favor the development of chronic kidney disease (CKD) and end-stage renal diseases [2-5]. Their

*Correspondence: keikoyk@med.niigata-u.ac.jp

${ }^{1}$ Department of Health Promotion Medicine, Niigata University Graduate School of Medical and Dental Sciences, Niigata, Japan

Full list of author information is available at the end of the article clustering also leads to cardiovascular disease and allcause death in the general population [6-8]. Although these traits are considered to be risk factors for CKD, little is known about their association with urinary biomarkers.

Urinary biomarkers can reflect pathophysiological changes in kidneys and thereby reveal links between physiological processes and diseases. The most common biomarkers for kidney damage are currently the serum creatine-based estimated glomerular filtration rate (eGFR) and proteinuria or albuminuria, which are also used to diagnose CKD [9]. A recent meta-analysis revealed that metabolic syndrome traits, with the 
exception of reduced high-density lipoprotein cholesterol levels, were significantly associated with albuminuria [10]. Although albuminuria is thought to be caused by morphological alterations in the glomerular filtration barrier, it might not specifically reflect pathological damage in the kidneys [11].

In addition to albuminuria and eGFR, several urinary biomarkers are focused on proximal tubular dysfunction $\left[\alpha_{1}\right.$-microglobulin $\left(\alpha_{1}-M G\right), \beta_{2}$-microglobulin $\left(\beta_{2}-M G\right)$, and $N$-acetyl $\beta$-D-glucosaminidase (NAG)]. Although these markers are related to diabetic kidney diseases [12], little is known about their relationship with metabolic syndrome traits.

Megalin, a glycoprotein member of the low-density lipoprotein receptor family, is primarily expressed at the apical membrane of proximal tubular epithelial cells, where it plays an important role in endocytic reabsorption [13]. We previously established a sandwich enzymelinked immunosorbent assay (ELISA) to measure the ectodomain (A-megalin) and full-length (C-megalin) forms of urinary megalin using monoclonal antibodies against the amino- and carboxy-terminals of megalin, respectively [14], and reported their clinical usefulness [15-17]. Podocalyxin (PCX), a transmembrane protein, is located at the apical membrane of glomerular podocytes and maintains the formation of intricate foot processes [18]. PCX has also been identified as a novel urinary biomarker for kidney diseases [19-21]. However, no studies have assessed the relationships of both megalin and PCX with metabolic risk factors in a general population.

In this context, the present study examined the association of urinary biomarkers with metabolic syndrome traits in a general population. Through comparison with traditional urinary biomarkers, including urinary albumin, we sought to identify potential novel urinary biomarkers that are related to the clustering of metabolic syndrome traits.

\section{Methods}

\section{Study participants}

This cross-sectional study was conducted by using data from a health checkup program performed as part of the Uonuma Resident Atherosclerosis Study by Anti-Sclerosis (URASA) study, Niigata, Japan. This study enrolled people who participated in a health checkup program from March 2014 to February 2016 at Yukiguni Yamato City Hospital, Niigata, Japan. Of the 352 participants, we excluded individuals with a non-fasting status $(n=2)$ and those with a urine albumin-to-creatinine ratio (ACR) of $300 \mathrm{mg} / \mathrm{g}(33.9 \mathrm{mg} / \mathrm{mmol})$ or more $(\mathrm{n}=3)$, leaving 347 participants as the analytic population. The study procedure was approved by the Ethics Committee of Niigata University School of Medicine (2015-1818).

\section{Traits of metabolic syndrome}

The evaluation of metabolic syndrome performed in this study was based on the traits of metabolic syndrome listed in the National Cholesterol Education Program-Adult Treatment Panel III [22]. Accordingly, we assessed the five following components: (i) abdominal obesity, defined as a waist circumference $\geq 90 \mathrm{~cm}$ in men and $\geq 80 \mathrm{~cm}$ in women; (ii) fasting plasma glucose $\geq 5.55 \mathrm{mmol} / \mathrm{L}$ or the use of any antidiabetic medications; (iii) triglyceride $\geq 1.69 \mathrm{mmol} / \mathrm{L}$ or the use of any antihyperlipidemic medications; (iv) high-density lipoprotein cholesterol $<1.03 \mathrm{mmol} / \mathrm{L}$ for men or $<1.29 \mathrm{mmol} / \mathrm{L}$ for women; and (v) systolic blood pressure $\geq 130 \mathrm{mmHg}$, diastolic blood pressure $\geq 85 \mathrm{mmHg}$, or use of any antihypertensive medications.

Waist circumference was measured by a trained healthcare professional, with the participant in the standing maximum expiratory position. Blood pressure was measured once by a pressurized cuff at the upper arm, with the participant in a sitting position. Plasma glucose was measured using the glucose oxidase electrode method. Triglyceride and high-density lipoprotein cholesterol were measured using the enzymatic method. Abdominal visceral fat area (VFA) was measured using a bioelectrical impedance analysis device (HDS-2000 DUALSCAN; Omron Healthcare, Co., Ltd., Kyoto, Japan), with the participant in the supine position. The measurement of VFA obtained by bioelectrical impedance analysis has previously been compared with that by computed tomography, and its accuracy was confirmed in the Asian population [23].

\section{Urinary biomarkers}

Spot urine samples were collected in the morning and were stored as $1-\mathrm{mL}$ aliquots at $-80^{\circ} \mathrm{C}$ on the same day. Urinary biomarkers were measured in the laboratory of Denka Co., Ltd. using stored frozen specimens. Megalin and PCX levels were measured by sandwich ELISAs as described previously $[14,20]$. There are two forms of megalin in urine: the ectodomain (A-megalin) and fulllength (C-megalin) forms. Briefly, we assessed A- and $\mathrm{C}$-megalin by ELISA using monoclonal antibodies against the amino- and carboxyl-termini of megalin, respectively [14]. The urinary PCX level was measured by ELISA using two antibody clones that recognize the intracellular region of human PCX [20]. Urinary concentrations of albumin and creatinine were measured by turbidimetric immunoassay and the enzymatic method, respectively. $\alpha_{1}$-MG and $\beta_{2}$-MG were measured by latex agglutination and NAG was measured by the colorimeter method. The level of each urinary biomarker was normalized to that of urinary creatinine. 


\section{Other covariates}

The general health checkups included a questionnaire, blood tests, and measurements of blood pressure, body weight, and height. The questionnaire, completed by the participants, included questions related to smoking and drinking habits, namely, whether the participant was a current smoker and whether the participant drank every day or not, respectively. Serum creatinine was measured by the enzymatic method and the eGFR was calculated as $194 \times[\text { serum creatinine }(\mathrm{mg} / \mathrm{dL})]^{-1.094} \times(\text { age })^{-0.287} \times$ 0.739 (if female) [24]. Diabetes was defined as a fasting plasma glucose $\geq 7.0 \mathrm{mmol} / \mathrm{L}, \mathrm{HbA} 1 \mathrm{c} \geq 6.5 \%$ (measured by high-performance liquid chromatography), or use of antidiabetic medication. Hypertension was defined as a systolic blood pressure $\geq 140 \mathrm{mmHg}$, diastolic blood pressure $\geq 90 \mathrm{mmHg}$, or use of antihypertensive medication. Body mass index (BMI) was calculated as body weight $(\mathrm{kg})$ divided by height squared $(\mathrm{m})^{2}$.

\section{Statistical analysis}

Participants' characteristics are shown as the mean [standard deviation (SD)] or percentage. We obtained Spearman's correlation coefficients for the number of metabolic syndrome traits and abdominal VFA. The urinary biomarker trend according to the number of metabolic risk factors was tested by linear regression analysis, which included each urinary biomarker (dependent variable) as a natural logarithm because of its skewed distribution.

Logistic regression analyses were performed to estimate the association between urinary biomarkers (independent variables) and the clustering of metabolic syndrome traits ( $\geq 3$, a dependent variable) [22]. Because there are no general standard ranges for urinary megalin and PCX, urinary biomarkers were divided by quartile into four groups in the logistic regression models. First, we ran the crude model between each urinary biomarker and dependent variable. Then, we adjusted the model by age and sex as a demographic-adjusted model. Finally, we ran the multivariable-adjusted model for the urinary biomarkers that were significantly associated with the clustering numbers of traits in the demographic-adjusted model, with adjustment by age, sex, and eGFR.

For sensitivity analyses, we estimated the association between abdominal VFA and urinary biomarkers in participants who underwent complete measurements $(\mathrm{n}=320)$. Linear regression analyzes were performed between abdominal VFA (independent variable) and each urinary biomarker (dependent variable). Crude, demographic-, and multivariable-adjusted logistic regression analyses were also performed between each urinary biomarker (independent variable) and abdominal visceral obesity (abdominal VFA $\geq 100 \mathrm{~cm}^{2}$, a dependent variable) [25]. The multivariable-adjusted model for significant urinary biomarkers was used in the demographic-adjusted model, with further adjustment for eGFR.

All analyses were performed using SAS version 9.4 (SAS Institute, Inc., Cary, NC).

\section{Results}

Characteristics of participants according to the number of metabolic syndrome traits

The mean age and eGFR of study participants were 61.3 (SD 8.4) years old and $74.8(\mathrm{SD} 13.6) \mathrm{mL} / \mathrm{min} / 1.73 \mathrm{~m}^{2}$, respectively. In total, 98 participants $(28.2 \%)$ with clustering of metabolic syndrome traits were included. The number of metabolic syndrome traits was correlated with abdominal VFA (Spearman's correlation coefficient $=0.60)$. In terms of the descriptive characteristics other than the diagnostic traits, participants who had four or more metabolic syndrome traits were older, male, had diabetes and hypertension, and had a larger abdominal VFA, lower eGFR, and higher BMI compared with those who had a lower number of traits (Table 1).

\section{Association between metabolic syndrome traits and urinary biomarkers}

Figure 1 shows the median (interquartile range) of each urinary biomarker according to the number of metabolic syndrome traits. Participants with a higher number of metabolic syndrome traits were likely to have higher $\beta_{2}$ MG ( $P$ trend $=0.024)$ and higher albumin, $\alpha_{1}-$ MG, and NAG (all $P$ trend $<0.001$ ).

The crude and adjusted odds ratios of the clustering numbers of metabolic syndrome traits for each urinary biomarker are shown in Table 2. After adjustment for age and sex, A-megalin and albumin had significantly higher odds ratios of a higher clustering number of metabolic syndrome traits. After further adjustment with eGFR, these associations of A-megalin and albumin remained significant $(P=0.027$ and $P=0.004$, respectively $)$ (Table 2).

\section{Association between abdominal visceral obesity and urinary biomarkers}

Abdominal VFA was significantly correlated with urinary albumin, A-megalin, $\alpha_{1}-\mathrm{MG}$, and NAG (all $P<0.05$ ) (Additional file 1: Table S1).

The crude and adjusted odds ratios of abdominal visceral obesity for each urinary biomarker are shown in Additional file 1: Table S2. After adjusting for age and sex, A-megalin, albumin, and NAG had significantly higher odds ratios for abdominal visceral obesity. After further adjustment with eGFR, the associations of A-megalin and 
Table 1 Descriptive characteristics according to the number of metabolic syndrome traits

\begin{tabular}{|c|c|c|c|c|c|}
\hline & \multicolumn{5}{|c|}{ Number of metabolic syndrome traits } \\
\hline & 0 & 1 & 2 & 3 & $\geq 4$ \\
\hline N & 60 & 101 & 88 & 65 & 33 \\
\hline Abdominal visceral fat area, $\mathrm{cm}^{2 \mathrm{a}}$ & $40.8(20.8)$ & $50.3(21.2)$ & $65.1(24.1)$ & $86.5(28.6)$ & $99.8(37.7)$ \\
\hline $\mathrm{eGFR}, \mathrm{mL} / \mathrm{min} / 1.73 \mathrm{~m}^{2}$ & $73.2(11.6)$ & $77.0(13.9)$ & $76.1(12.8)$ & $74.1(12.4)$ & $68.6(18.1)$ \\
\hline Age, years & $58.1(8.9)$ & $59.7(7.9)$ & $62.3(8.2)$ & $64.6(8.0)$ & $63.2(7.9)$ \\
\hline Male sex, $\%$ & 35.0 & 46.5 & 59.1 & 64.6 & 63.6 \\
\hline Body mass index, $\mathrm{kg} / \mathrm{m}^{2}$ & $20.6(2.1)$ & $22.0(2.5)$ & $23.0(2.9)$ & $24.9(2.5)$ & $26.3(3.0)$ \\
\hline Waist circumference, $\mathrm{cm}$ & $75.7(5.8)$ & $80.4(7.2)$ & $83.1(7.8)$ & $89.1(6.3)$ & $92.8(7.4)$ \\
\hline Current smoker, $\%$ & 11.7 & 13.9 & 11.4 & 7.7 & 12.1 \\
\hline Drink alcohol every day, $\%$ & 23.3 & 24.8 & 39.8 & 44.6 & 12.1 \\
\hline Systolic blood pressure, mmHg & $114(9)$ & $123(17)$ & $130(18)$ & $133(14)$ & $136(16)$ \\
\hline Diastolic blood pressure, $\mathrm{mmHg}$ & $69(7)$ & $74(11)$ & $78(12)$ & $81(10)$ & $83(10)$ \\
\hline Use of any antihypertensive medication, $\%$ & 0 & 12.9 & 22.7 & 50.8 & 60.6 \\
\hline Fasting plasma glucose, mmol/L & $5.05(0.34)$ & $5.25(0.57)$ & $5.65(0.75)$ & $6.06(1.03)$ & $6.62(1.82)$ \\
\hline $\mathrm{HbA} 1 \mathrm{c}, \%$ & $5.6(0.2)$ & $5.7(0.4)$ & $5.8(0.4)$ & $6.0(0.5)$ & $6.4(1.0)$ \\
\hline Use of any antidiabetic medication, $\%$ & 0 & 1.0 & 3.4 & 7.7 & 18.2 \\
\hline Diabetes, $\%$ & 0 & 3.0 & 6.8 & 20.0 & 36.4 \\
\hline Hypertension, \% & 0 & 25.7 & 44.3 & 66.2 & 75.8 \\
\hline
\end{tabular}

Data are shown as mean (SD) or percentage

eGFR estimated glomerular filtration rate

${ }^{\text {a }}$ The number of participants decreased by $8,6,8,3$, and 2 , respectively

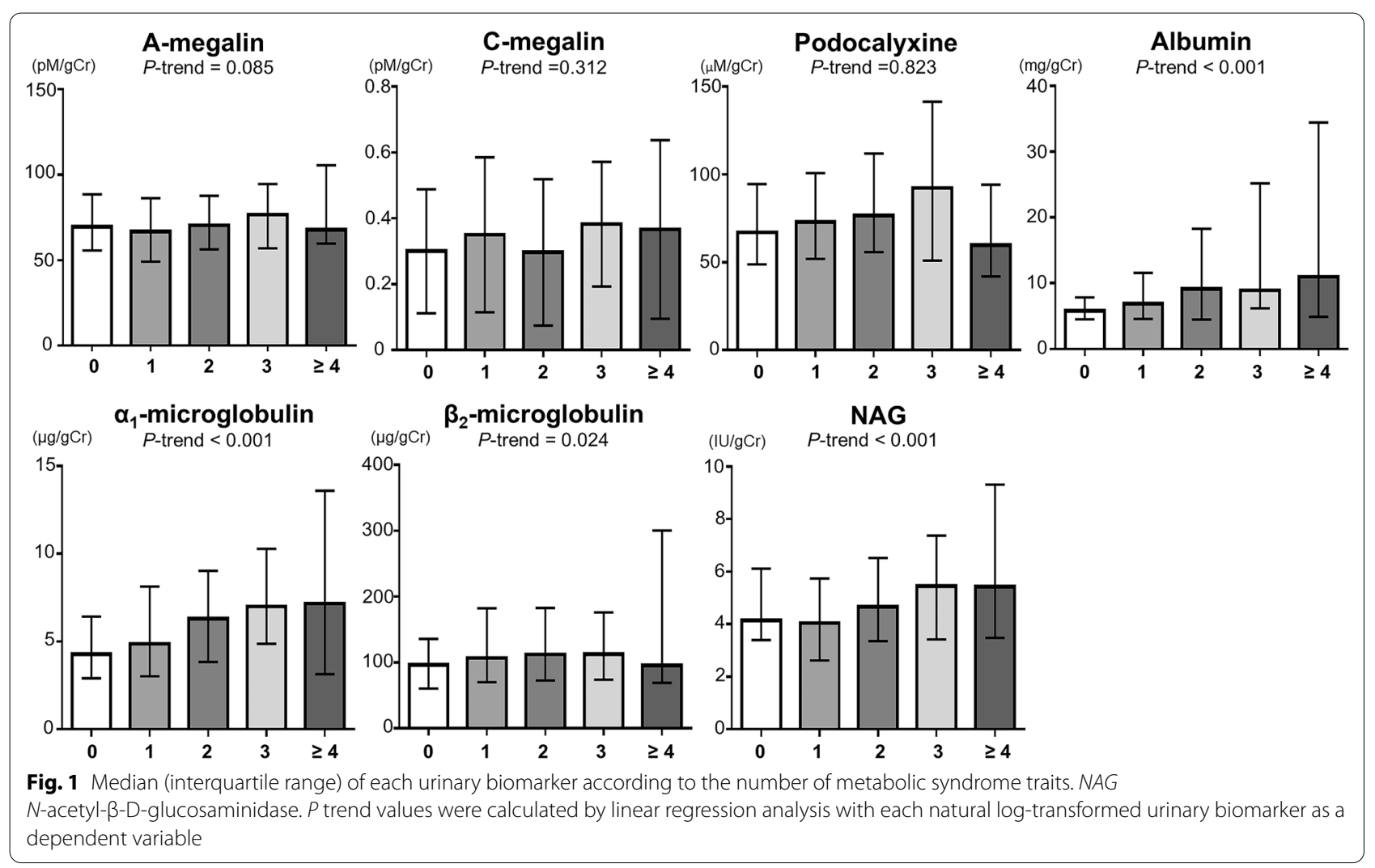


Table 2 Logistic regression analysis between urinary biomarkers and the clustering number of metabolic syndrome traits ( $\geq 3$ )

\begin{tabular}{|c|c|c|c|c|c|c|}
\hline & \multicolumn{2}{|l|}{ Crude } & \multicolumn{2}{|c|}{ Demographic-adjusted } & \multicolumn{2}{|c|}{ Multivariable-adjusted } \\
\hline & Odds ratio $(95 \% \mathrm{Cl})$ & $P$ value & Odds ratio $(95 \% \mathrm{Cl})$ & $P$ value & Odds ratio $(95 \% \mathrm{CI})$ & $P$ value \\
\hline Albumin & $1.45(1.16,1.80)$ & $<0.001$ & $1.43(1.13,1.80)$ & 0.003 & $1.42(1.12,1.79)$ & 0.004 \\
\hline A-megalin & $1.20(0.97,1.48)$ & 0.091 & $1.29(1.03,1.61)$ & 0.028 & $1.30(1.03,1.64)$ & 0.027 \\
\hline C-megalin & $1.14(0.93,1.41)$ & 0.217 & $1.06(0.86,1.32)$ & 0.582 & & \\
\hline Podocalyxin & $1.06(0.86,1.30)$ & 0.605 & $0.996(0.80,1.24)$ & 0.975 & & \\
\hline$a_{1}$-microglobulin & $1.38(1.11,1.71)$ & 0.004 & $1.19(0.94,1.50)$ & 0.146 & & \\
\hline$\beta_{2}$-microglobulin & $1.08(0.88,1.34)$ & 0.463 & $1.04(0.83,1.29)$ & 0.761 & & \\
\hline NAG & $1.36(1.09,1.68)$ & 0.006 & $1.18(0.93,1.49)$ & 0.182 & & \\
\hline
\end{tabular}

Each urinary biomarker is treated as a quartile. The demographic-adjusted model includes age and male sex. The multivariable-adjusted model includes age (continuous), male sex, and eGFR (continuous)

$N A G N$-acetyl- $\beta$-D-glucosaminidase

albumin remained significant $(P=0.002$ and $P=0.030$, respectively) (Additional file 1: Table S2).

\section{Discussion}

This cross-sectional study examined the associations of the clustering numbers of metabolic syndrome traits with urinary biomarkers in the general adult population. We found that urinary A-megalin and albumin were each independently associated with the clustering number of metabolic syndrome traits. Corresponding results using abdominal VFA were similar to those of the clustering number of metabolic syndrome traits. Among them, the association of albumin was in line with the results of previous studies $[10,26]$. However, to our knowledge, this is the first study to detect an association of the clustering numbers of metabolic syndrome traits with A-megalin, suggesting that urinary A-megalin could be a potential marker for kidney damage due to metabolic risk factors.

A number of studies have demonstrated a significant association between albuminuria and the clustering of metabolic syndrome traits. However, the pathway is not fully understood. Albuminuria has been associated with inflammation and insulin resistance, regardless of diabetes [27]. These conditions are also hallmarks of metabolic syndrome and may lead to albuminuria $[28,29]$. Moreover, albuminuria has been recognized as a multifactorial marker of kidney damage, including glomerular barrier damage, tubulointerstitial alteration, and kidney endothelial dysfunction [30]. However, based on the present findings (i.e., ACR, 0-299 mg/g), these hallmarks may affect the kidneys, in particular, the tubulointerstitial condition. This is because we found a significant association of the clustering of metabolic risk traits with not only urinary albumin but also A-megalin.

Megalin is recognized as an endocytic receptor involved in the proximal tubular uptake of various proteins, including albumin, $\alpha_{1}-\mathrm{MG}, \beta_{2}-\mathrm{MG}$, and liver-type fatty acid-binding protein [31]. It is located at the brush border, undergoes intracellular trafficking, and is shed by a mechanism that has not yet been completely elucidated. Urinary A-megalin (the ectodomain form of megalin) may reflect the recycling activity of megalin in proximal tubular epithelial cells [32] and might be increased due to endocytic metabolic loads to the cells. In contrast, urinary $\mathrm{C}$-megalin or full-length megalin is correlated with the severity of diabetic kidney disease [14] and IgA nephropathy [15], which reflects established metabolic overload or damage in the endolysosomal systems of the cells and is excreted by exocytosis [33]. In the present study, there was a discrepancy between the results for A-megalin and other tubular markers (i.e., $\alpha_{1}$-MG, $\beta_{2}-\mathrm{MG}$, and NAG). Megalin is likely to be a key molecule that triggers tubular injury [34], which might increase the levels of these urinary tubular markers. Although further studies are needed to resolve this discrepancy, our findings suggest that urinary A-megalin might possibly have a different significance from other tubular markers.

Meanwhile, the present study did not show any independent association of urinary PCX with the clustering of metabolic risk traits. Urinary PCX originates mainly from the glomeruli in the kidneys [35] and is increased significantly in podocyte-injured patients (e.g., those with diabetes, kidney disease, nephrotic syndrome, and other active glomerulonephritis) [19]. Hence, our findings suggest that this "preclinical" phase of renal metabolic load associated with traits of metabolic syndrome may not involve podocytes but rather proximal tubular epithelial cells. Indeed, by examining pathological changes in the kidney, Alexander et al. found that metabolic syndrome induces renal parenchymal damages, such as tubular atrophy, interstitial fibrosis, and arterial sclerosis, but that there was no difference between groups with and without metabolic syndrome in glomerular volume [36]. 
Several limitations should be discussed. First, the association between each urinary biomarker and the metabolic syndrome traits was adjusted with known confounding factors, such as kidney function. However, we cannot fully exclude the residual confounding. For example, because only self-reported prescription information was available in the present study, we cannot detect who was receiving renin-angiotensin-aldosterone system inhibitors or sodium-glucose cotransporter-2 inhibitors, which could confound this association. Second, urinary biomarkers were measured only once, which might cause a misunderstanding of chronicity. Finally, because of the cross-sectional observational study design, we cannot determine temporality and causality.

\section{Conclusions}

Our study found that both urinary A-megalin and albumin were independently associated with the clustering numbers of metabolic syndrome traits in Japanese adults. Our findings further support an indicative role for urinary A-megalin in kidney damage, which could be induced by the clustering of metabolic risk traits.

\begin{abstract}
Abbreviations
$a_{1}-M G$ : $a_{1}$-microglobulin; ACR: Urine albumin-to-creatinine ratio; $\beta_{2}-M G$ : $\beta_{2}$-microglobulin; BMI: Body mass index; CKD: Chronic kidney disease; eGFR: Estimated glomerular filtration rate; ELISA: Enzyme-linked immunosorbent assays; NAG: $N$-acetyl- $\beta$-D-glucosaminidase; PCX: Podocalyxin; SD: Standard deviation; VFA: Visceral fat area.
\end{abstract}

\section{Supplementary Information}

The online version contains supplementary material available at https://doi. org/10.1186/s13098-021-00779-5.

Additional file 1: Table S1. Linear regression analysis between abdominal visceral fat area and urinary biomarkers. Table S2. Logistic regression analysis between urinary biomarkers and abdominal visceral obesity.

\section{Acknowledgements}

The authors thank all the study participants and the institutions of Niigata Prefecture and Yukiguni Yamato City Hospital, Niigata, Japan, for their cooperation. The authors would also like to thank Hiroyuki Kurosawa, Yoshiaki Hirayama, and Denka Co. Ltd. for performing measurements of urinary biomarkers and for providing other assistance. For this research, we were kindly granted access to a supercomputer at the Academic Centre for Computing and Media Studies, Kyoto University, Japan.

\section{Authors' contributions}

$\mathrm{KK}, \mathrm{MHOS}, \mathrm{YI}, \mathrm{JT}, \mathrm{IN}$, and AS created the concept of the study and contributed to its design; $\mathrm{YI}, \mathrm{KM}$, and JT conducted the research; $\mathrm{KK}$, MHos, and KN contributed to the statistical analysis and interpretation of data, KK, MHos, and AS drafted the paper; KM, MHar, KN, IN, and AS provided critical review, advice, and consultation throughout. All authors have read and approved the final manuscript.

\section{Funding}

This work was supported by funding from Niigata Prefecture. The funder played no role in the study design, data analysis, interpretation of results, or publication of the manuscript.

\section{Availability of data and materials}

We cannot provide individual data because we did not obtain consent from the study participants to share individual data publicly. However, the minimum dataset may be made available upon reasonable request, with ethical approval by the Ethics Committee of Niigata University.

\section{Declarations}

Ethics approval and consent to participate

The study procedure was approved by the Ethics Committee of Niigata University School of Medicine (2015-1818). Written informed consent was obtained from all participants.

\section{Consent for publication}

Not applicable.

\section{Competing interests}

AS has received research grants from Denka Co. Ltd.

\section{Author details}

'Department of Health Promotion Medicine, Niigata University Graduate School of Medical and Dental Sciences, Niigata, Japan. ${ }^{2}$ Division of Clinical Nephrology and Rheumatology, Kidney Research Center, Niigata University Graduate School of Medical and Dental Sciences, Niigata, Japan. ${ }^{3}$ Department of Clinical Nutrition Science, Kidney Research Center, Niigata University Graduate School of Medical and Dental Sciences, Niigata, Japan. ${ }^{4}$ Yukiguni Yamato City Hospital, Minamiuonuma, Niigata, Japan. ${ }^{5}$ Iwamuro Health Promotion Center, Niigata, Japan. ${ }^{6}$ Division of Preventive Medicine, Niigata University Graduate School of Medical and Dental Sciences, Niigata, Japan. ${ }^{7}$ Department of Applied Molecular Medicine, Kidney Research Center, Niigata University Graduate School of Medical and Dental Sciences, Niigata, Japan.

Received: 19 October 2021 Accepted: 28 December 2021

Published online: 15 January 2022

\section{References}

1. Kibria GMA, Crispen R. Prevalence and trends of chronic kidney disease and its risk factors among US adults: an analysis of NHANES 2003-18. Prev Med Rep. 2020;20:101193

2. Thomas G, Sehgal AR, Kashyap SR, Srinivas TR, Kirwan JP, Navaneethan SD Metabolic syndrome and kidney disease: a systematic review and metaanalysis. Clin J Am Soc Nephrol. 2011;6:2364-73.

3. Yun HR, Kim H, Park JT, Chang TI, Yoo TH, Kang SW, Choi KH, Sung S, Kim SW, Lee J, Oh KH, Ahn C, Han SH, Korean Cohort Study for Outcomes in Patients With Chronic Kidney Disease (KNOW-CKD) Investigators. Obesity, metabolic abnormality, and progression of CKD. Am J Kidney Dis. 2018;72:400-10.

4. Tozawa M, Iseki C, Tokashiki K, Chinen S, Kohagura K, Kinjo K, Takishita S, Iseki K. Metabolic syndrome and risk of developing chronic kidney disease in Japanese adults. Hypertens Res. 2007;30:937-43.

5. Panwar B, Hanks LJ, Tanner RM, Muntner P, Kramer H, McClellan WM Warnock DG, Judd SE, Gutiérrez OM. Obesity, metabolic health, and the risk of end-stage renal disease. Kidney Int. 2015;87:1216-22.

6. Malik S, Wong ND, Franklin SS, Kamath TV, L'Italien GJ, Pio JR, Williams GR. Impact of the metabolic syndrome on mortality from coronary heart disease, cardiovascular disease, and all causes in United States adults. Circulation. 2004:110:1245-50.

7. Iseki K, Konta T, Asahi K, Yamagata K, Fujimoto S, Tsuruya K, Narita I, Kasahara M, Shibagaki Y, Moriyama T, Kondo M, Iseki C, Watanabe T. Impact of metabolic syndrome on the mortality rate among participants in a specific health check and guidance program in Japan. Intern Med. 2020;59:2671-8.

8. Saito I, Iso H, Kokubo Y, Inoue M, Tsugane S. Metabolic syndrome and allcause and cardiovascular disease mortality: Japan Public Health Centerbased Prospective (JPHC) Study. Circ J. 2009;73:878-84.

9. Kidney Disease Improving Global Outcomes (KDIGO) CKD Work Group. KDIGO 2012 clinical practice guideline for the evaluation and management of chronic kidney disease. Kidney Int Suppl. 2013;3:1-150. 
10. Rashidbeygi E, Safabakhsh M, Delshad Aghdam S, Mohammed SH, Alizadeh S. Metabolic syndrome and its components are related to a higher risk for albuminuria and proteinuria: evidence from a metaanalysis on 10,603,067 subjects from 57 studies. Diabetes Metab Syndr. 2019;13:830-43.

11. Butt L, Unnersjö-Jess D, Höhne M, Edwards A, Binz-Lotter J, Reilly D, Hahnfeldt R, Ziegler V, Fremter K, Rinschen MM, Helmstädter M, Ebert LK, Castrop H, Hackl MJ, Walz G, Brinkkoetter PT, Liebau MC, Tory K, Hoyer PF, Beck BB, Brismar H, Blom H, Schermer B, Benzing T. A molecular mechanism explaining albuminuria in kidney disease. Nat Metab. 2020;2:461-74.

12. Colhoun HM, Marcovecchio ML. Biomarkers of diabetic kidney disease. Diabetologia. 2018;61:996-1011.

13. Saito A, Takeda T, Hama H, Oyama Y, Hosaka K, Tanuma A, Kaseda R, Ueno M, Nishi S, Ogasawara S, Gondaira F, Suzuki Y, Gejyo F. Role of megalin, a proximal tubular endocytic receptor, in the pathogenesis of diabetic and metabolic syndrome-related nephropathies: protein metabolic overload hypothesis. Nephrology. 2005;10(suppl):S26-31.

14. Ogasawara S, Hosojima M, Kaseda R, Kabasawa H, Yamamoto-Kabasawa K, Kurosawa H, Sato H, lino N, Takeda T, Suzuki Y, Narita I, Yamagata K, Tomino Y, Gejyo F, Hirayama Y, Sekine S, Saito A. Significance of urinary full-length and ectodomain forms of megalin in patients with type 2 diabetes. Diabetes Care. 2012;35:1112-8.

15. Seki T, Asanuma K, Asao R, Nonaka K, Sasaki Y, Oliva Trejo JA, Kurosawa $H$, Hirayama $Y$, Horikoshi S, Tomino Y, Saito A. Significance of urinary full-length megalin in patients with IgA nephropathy. PLOS ONE. 2014;9:e114400

16. Toi N, Inaba M, Ishimura E, Tsugawa N, Imanishi Y, Emoto M, Hirayama Y, Nakatani S, Saito A, Yamada S. Significance of urinary C-megalin excretion in vitamin D metabolism in pre-dialysis CKD patients. Sci Rep. 2019;9:2207.

17. Shoji S, Hosojima M, Kabasawa H, Kondo R, Miura S, Watanabe S, Aoki N Kaseda R, Kuwahara S, Tanabe N, Hirayama Y, Narita I, Kikuchi T, Kagamu $\mathrm{H}$, Saito A. Correlation of prechemotherapy urinary megalin ectodomain (A-megalin) levels with the development of cisplatin-induced nephrotoxicity: a prospective observational study. BMC Cancer. 2019;19:1170.

18. Nielsen JS, MCNagny KM. The role of podocalyxin in health and disease. J Am Soc Nephrol. 2009;20:1669-76.

19. Hara M, Yamagata K, Tomino Y, Saito A, Hirayama Y, Ogasawara S, Kurosawa $\mathrm{H}$, Sekine S, Yan K. Urinary podocalyxin is an early marker for podocyte injury in patients with diabetes: establishment of a highly sensitive ELISA to detect urinary podocalyxin. Diabetologia. 2012;55:2913-9.

20. Asao R, Asanuma K, Kodama F, Akiba-Takagi M, Nagai-Hosoe Y, Seki T, Takeda Y, Ohsawa I, Mano S, Matsuoka K, Kurosawa H, Ogasawara S, Hirayama Y, Sekine S, Horikoshi S, Hara M, Tomino Y. Relationships between levels of urinary podocalyxin, number of urinary podocytes, and histologic injury in adult patients with IgA nephropathy. Clin J Am Soc Nephrol. 2012;7:1385-93

21. Imaizumi T, Nakatochi M, Akiyama S, Yamaguchi M, Kurosawa H, Hirayama Y, Katsuno T, Tsuboi N, Hara M, Maruyama S. Urinary podocalyxin as a biomarker to diagnose membranous nephropathy. PLoS ONE. 2016;11:e0163507.

22. Grundy SM, Cleeman JI, Daniels SR, Donato KA, Eckel RH, Franklin BA, Gordon DJ, Krauss RM, Savage PJ, Smith SC Jr, Spertus JA, Costa F. Diagnosis and management of the metabolic syndrome: an American Heart Association/National Heart, Lung, and Blood Institute Scientific Statement. Circulation. 2005;112:2735-52

23. Park KS, Lee DH, Lee J, Kim YJ, Jung KY, Kim KM, Kwak SH, Choi SH, Park KS, Jang HC, Lim S. Comparison between two methods of bioelectrical impedance analyses for accuracy in measuring abdominal visceral fat area. J Diabetes Complicat. 2016;30:343-9.

24. Matsuo S, Imai E, Horio M, Yasuda Y, Tomita K, Nitta K, Yamagata K, Tomino Y, Yokoyama H, Hishida A, Collaborators developing the Japanese equation for estimated GFR. Revised equations for estimated GFR from serum creatinine in Japan. Am J Kidney Dis. 2009;53:982-92.

25. Examination Committee of Criteria for 'Obesity Disease' in Japan; Japan Society for the Study of Obesity. New criteria for 'obesity disease' in Japan. Circ J. 2002;66:987-92.

26. Tamba S, Nakatsuji H, Kishida K, Noguchi M, Ogawa T, Okauchi Y, Nishizawa H, Imagawa A, Nakamura T, Matsuzawa Y, Funahashi T, Shimomura I. Relationship between visceral fat accumulation and urinary albumin-creatinine ratio in middle-aged Japanese men. Atherosclerosis. 2010;211:601-5.

27. Zhang X, Lerman LO. The metabolic syndrome and chronic kidney disease. Transl Res. 2017;183:14-25.

28. Groop PH, Forsblom C, Thomas MC. Mechanisms of disease: pathwayselective insulin resistance and microvascular complications of diabetes. Nat Clin Pract Endocrinol Metab. 2005;1:100-10.

29. Jheng HF, Tsai PJ, Chuang YL, Shen YT, Tai TA, Chen WC, Chou CK, Ho LC, Tang MJ, Lai KT, Sung JM, Tsai YS. Albumin stimulates renal tubular inflammation through an HSP70-TLR4 axis in mice with early diabetic nephropathy. Dis Model Mech. 2015;8:1311-21.

30. de Zeeuw D, Parving HH, Henning $\mathrm{RH}$. Microalbuminuria as an early marker for cardiovascular disease. J Am Soc Nephrol. 2006;17:2100-5.

31. Christensen El, Birn H. Megalin and cubilin: synergistic endocytic receptors in renal proximal tubule. Am J Physiol Renal Physiol. 2001;280:F562-73.

32. Suruda C, Tsuji S, Yamanouchi S, Kimata T, Huan NT, Kurosawa H, Hirayama Y, Tsukaguchi H, Saito A, Kaneko K. Decreased urinary excretion of the ectodomain form of megalin (A-megalin) in children with OCRL gene mutations. Pediatr Nephrol. 2017;32:621-5.

33. De S, Kuwahara S, Hosojima M, Ishikawa T, Kaseda R, Sarkar P, Yoshioka Y, Kabasawa H, lida T, Goto S, Toba K, Higuchi Y, Suzuki Y, Hara M, Kurosawa $H$, Narita I, Hirayama Y, Ochiya T, Saito A. Exocytosis-mediated urinary full-length megalin excretion is linked with the pathogenesis of diabetic nephropathy. Diabetes. 2017;66:1391-404

34. Kuwahara S, Hosojima M, Kaneko R, Aoki H, Nakano D, Sasagawa T, Kabasawa H, Kaseda R, Yasukawa R, Ishikawa T, Suzuki A, Sato H, Kageyama S, Tanaka T, Kitamura N, Narita I, Komatsu M, Nishiyama A, Saito A. Megalinmediated tubuloglomerular alterations in high-fat diet-induced kidney disease. J Am Soc Nephrol. 2016;27:1996-2008.

35. Hara M, Yanagihara T, Kihara I, Higashi K, Fujimoto K, Kajita T. Apical cell membranes are shed into urine from injured podocytes: a novel phenomenon of podocyte injury. J Am Soc Nephrol. 2005;16:408-16.

36. Alexander MP, Patel TV, Farag YM, Florez A, Rennke HG, Singh AK. Kidney pathological changes in metabolic syndrome: a cross-sectional study. Am J Kidney Dis. 2009;53:751-9.

\section{Publisher's Note}

Springer Nature remains neutral with regard to jurisdictional claims in published maps and institutional affiliations.

Ready to submit your research? Choose BMC and benefit from

- fast, convenient online submission

- thorough peer review by experienced researchers in your field

- rapid publication on acceptance

- support for research data, including large and complex data types

- gold Open Access which fosters wider collaboration and increased citations

- maximum visibility for your research: over $100 \mathrm{M}$ website views per year

At BMC, research is always in progress.

Learn more biomedcentral.com/submissions 